\title{
article
}

\section{Memorable life events and disclosure of child sexual abuse: Possibilities and challenges across diverse contexts}

\author{
Debra Sue Allnock, debra.allnock@beds.ac.uk \\ University of Bedfordshire, Luton, UK
}

\begin{abstract}
This article examines the relationship between memorable life events (MLEs) and disclosure of sexual abuse in childhood. The findings derive from a larger thematic and phenomenological analysis of MLEs across the life course of 12 adults with self-reported histories of child sexual abuse (CSA). Participants were recruited from the UK, but represent a diverse group in terms of age, gender, country of origin, sexuality and disability. In-depth interviews and Life History Calendars (LHCs) were used to collect a range of contextual and event-based data. Varied and unique MLEs were found to promote disclosure of sexual abuse in childhood, although this was highly contingent on context. A conceptual framework is offered as a way of navigating this relationship and contexts that can inhibit, alter or reverse decisions to disclose abuse. This research is the first known in-depth analysis of MLEs and CSA, and therefore makes an original contribution to the field.
\end{abstract}

key words child sexual abuse $\cdot$ disclosure $\cdot$ life events $\cdot$ life course

\section{Introduction}

Child sexual abuse (CSA) is a largely silent and witness-free crime. Given these characteristics, disclosure of CSA is seen by many researchers and practitioners as a key site for intervention (Hershkowitz et al, 2007). In response, 'disclosure' has become an established sub-field of the CSA international literature. For victims of CSA, disclosure of or telling about their abuse has been found to be important in stopping it, seeking emotional support, protecting other children and seeking justice for themselves and others (Allnock and Miller, 2013). Professionals are concerned with official disclosures because, during investigations, there is often a lack of corroborating physical and medical evidence and witness statements are often missing (Roberts and Powell, 2001). While disclosures may be seen by professionals to be crucial to their work in keeping children safe, the experiences of individuals in disclosing abuse is not always a positive one (Ullman and Filipas, 2005).This study examines a previously neglected perspective on disclosure and telling, examining the ways in which memorable life events (MLEs) may influence this process. 


\section{Investigating change across the life course}

Within the social sciences, and more specifically within life course research, there is a relatively large field of study that investigates life events. A life event is defined as a significant occurrence involving a relatively abrupt change with the potential to produce serious and long-lasting effects (Hutchinson, 2010). Researchers have conceptually imagined the 'life event' in terms of its consequences for change across the life course. Giddens (1991:112-13), for example, proposed the theoretical construct of 'fateful moments' which are 'those when individuals are called on to take decisions that are particularly consequential for their ambitions, or more generally for their future lives. These are times when events come together in such a way that an individual stands, as it were, at a crossroads in his existence.' Giddens identifies fateful moments as those that constitute non-routinised moments that are consequential to the life course.Turning points are also conceptually applied in a range of disciplines to examine change across the life course. They are defined as alterations to or deflections from a long-term pathway or life trajectory and - importantly - they are understood to have been initiated at an earlier point in time (Sampson and Laub, 2005). Turning points have been particularly useful in criminological studies for investigating experiences of and changes in offending (see Carlsson, 2012; Ladlow and Neale, 2016). Change is not always conceived of as 'big'. Changes can be small, incremental and may accumulate over time, via incremental 'nudges', 'eddies' or 'drifts' (Carlsson, 2012; Ladlow and Neale, 2016). Concepts such as turning points and fateful moments can usefully be identified in personal biographical narratives using 'critical moments' as a technique for analysis (Thomson et al, 2002: 339).

Life events have also been of interest in the field of psychology. Pillemer $(1998,2001)$ was interested in the rare and unique moments in everyday life that are punctuated by distinctive, emotional and highly influential episodes (Pillemer, 1998, 2001). Pillemer was interested in the way that such events - which he viewed through the lens of personal event memories - function in storytelling. He defined a personal event memory as an individual's memory of an event from a certain moment in time. The defining characteristics of a personal event memory are that (1) they usually include vivid multi-sensory elements; (2) they are usually recalled in detail; and (3) they are usually believed by the individual to be an accurate representation of the event. Pillemer argues that they serve important psychological functions by influencing, inspiring and directing actions and beliefs long after the event itself.

The third characteristic of a personal event memory, as noted above, is critical in understanding individuals' memories from childhood. Current knowledge about memory deriving from behavioural and neurobiological studies demonstrates that adult memories of childhood are reconstructions based on current motivations and world knowledge (Howe, 2013; Conway et al, 2014). Modern views of memory suggest that memories are prone to error and falsity, and are not full recollections of an experience.As Pillemer notes, they may have alternate functions such as driving social interactions and generating meaning in human lives (see also Conway et al, 2014). 


\section{Understanding how memorable life events may interact with disclosure of child sexual abuse}

Little in-depth attention has been given to the concepts of fateful moments, turning points or MLEs - as reflected in personal event memories - in the field of CSA and even less so in the consideration of these concepts as recalled by research participants relating to their childhood years. Some studies specific to disclosure of CSA have noted the important role that external events, precipitants or 'stimuli' play, although these are often 'buried' in the broader findings of research and not treated as the key focus of interest. Campis et al's (1993) research, which examined medical records for reasons why children disclosed to professionals, is the earliest study identified which found that external events played a key role in 'accidental' disclosures by children. London et al's (2005) review of disclosure found that simply being prompted to discuss abuse could provide the impetus for children to tell. Malloy, Brubacher and Lamb's (2013) study of investigative interviews with 204 children and young people found that $54 \%$ of children who gave reasons for disclosing were motivated to tell following an external precipitant, such as watching a television programme in which sexual abuse was a theme. Qualitative studies such as Jensen et al's (2005), Cossar et al's (2013) and Allnock and Miller's (2013) found that discussions, conversations and watching television programmes could provide important catalysts for recognition of abuse, usually as children were transitioning into adolescence and diversifying their social networks. Findings from studies on positive adaptation also identify the role of external precipitants as important in moving on from CSA (Bogar and Hulse-Killacky, 2006; Roller et al, 2009; Arias and Johnson, 2013). Roller et al (2009) considered how critical events could be considered negative in relation to sexuality, such as a sexual assault; others could be considered positive, such as a spiritual awakening; or some could be considered 'developmental', such as the birth of a child. Indeed, Banyard and Williams' (2007) study on recovery with 21 women uncovered turning points such as the birth of a child as precipitating important life changes.

While the studies mentioned above provide some clues as to the importance of external precipitants in facilitating disclosure of abuse, few of these researchers actively conceptualised these as life events per se, and so it is not possible to know whether participants would have identified them, without prompting, as important to their life course more generally. No other studies could be identified in the field of CSA more generally, or within the field of disclosure more specifically, that have investigated, in-depth, the role of MLEs in the process of disclosure, making this study unique in its findings.

\section{The study}

This study makes an original contribution to the evidence base on disclosure of CSA by examining the ways in which MLEs - as viewed through the lens of personal event memories - influence disclosure in childhood. These findings derive from a larger study of MLEs and their impact on self-reported change across the life course of adults with histories of CSA.The findings presented here focus specifically on the accounts of childhood provided by the participants, where childhood was considered to constitute ages up to 12 . While the full study sample was 12 , the findings presented here are based on the accounts of nine adults. Two of the 12 participants did not recall 
their abuse in childhood, only becoming aware of it in adolescence, and the third participant's abuse did not begin until adolescence. Therefore these three participants did not provide detailed accounts of their childhood period.

The underpinning theoretical framework of this research is the life course perspective. A life course approach emphasises a temporal and social perspective, looking back across an individual's or a cohort's life experiences or across generations for clues to current patterns of health, development or wellbeing, while recognising that both past and present experiences are shaped by the wider social, economic and cultural context (Hutchinson, 2010). In this research, I adopted Holstein and Gubrium's (2000) understanding of the life course as a socially constructed phenomenon. Holstein and Gubrium argue that: 'Person's depictions of, and dealings with, their social worlds create or constitute those social worlds as meaningful phenomena' (2000:31). This is not to suggest that the life course is 'ephemeral', without substance. Rather, what is meaningful about the life course are individuals' experiences of it and the subsequent meanings they attach to it. This is of interest in attempting to understand the ways in which individuals construct personal event memories for clues to the way in which meaningful change (in this particular article, disclosure) is accomplished following CSA.

\section{Methodology}

In-depth interviews were undertaken by the author between January and August 2011, producing substantial narratives for each of the 12 participants. A semistructured interview guide was developed to capture the key elements of the life course framework: (1) location in time and place; (2) linked lives; (3) human agency; and (4) timing of lives (Giele and Elder, 1998). The tool provided the opportunity to generate a wealth of rich and vibrant data yet also to support the generation of comparable qualitative data.

Alongside the interviews, the author and participants jointly completed a Life History Calendar (LHC).A LHC (also referred to as a Life Grid) is a chart that details experiences year by year, blending key moments in the life course - key personal trajectories/transitions as well as external historical events - with specific research questions designed to gain a holistic picture of a participant's life course over time (Del Bianco, 2015). Historically the purpose of using Life Grids/LHCs has been to minimise error in recall by enhancing memory retrieval through autobiographical memory processes (Morselli et al, 2016). For example, it is argued that using this method can assist individuals to engage 'flashbulb' memories (Berney and Blane, 1997) to help them remember details about particular days or events in their past. These tools are also recognised as a useful way to facilitate flexible interaction between the participant and researcher who can clarify intended meanings in reconstructing the past (Belli, 1988). Importantly, this study takes a social constructionist approach that recognises that individuals create meaning from the life course. As such, precise accuracy in the detail of events was not the end goal. Rather, the LHC was used as a tool to jog memory about specific events, but in a way that supported participants to reflect on the meaning of those events. It also allowed the collection of a broad and complex range of contextual data, and enabled focused comparison across the different age groups of the sample. 
The tool that was chosen for adaptation and use in this study was an expanded LHC initially developed by Freedman et al (1988) and adapted to include broader age ranges and a technique for incorporating 'landmark events' as identified by participants (Loftus and Marburger, 1983; Axinn et al, 1999).

\section{Procedures and ethics}

The participants were recruited using a purposive sampling technique, without the use of incentives, through advertisements posted on the National Society for the Prevention of Cruelty to Children's (NSPCC) website, and distributed via a select number of therapeutic services and conferences on CSA.The advertisement contained the project title, and specified the characteristics/experiences sought for the study, thus all participants' self-reported experiences of CSA. Potential candidates were asked to email the author to indicate their interest, following which the author responded with a more detailed information sheet and requested a telephone call with them to explain the study in more detail. A total of 20 potential candidates contacted the author, of which 18 agreed to a telephone call. Of these, 12 agreed to participate. Interviews occurred primarily in participants' homes, with three participants interviewed on the premises of a national charity. The interviews lasted between 90 and 180 minutes, and one participant was interviewed over the course of three meetings.

Ethical approval for this research was sought and provided by the NSPCC Research Ethics Committee and the University of Bristol, School for Policy Studies Ethics Committee. All participant names have been changed to protect anonymity.

\section{Data analysis}

Grounded in a constructivist ontology and interpretivist epistemology (Denzin and Lincoln, 2005), the main methodological approach to analysis drew on phenomenological reduction in which descriptive and interpretive analyses were conducted. Phenomenological reduction (or epoché), popularised in philosophy by Edward Husserl, is a process whereby the phenomenologist overtly seeks to block biases and assumptions in order to explain a phenomenon in terms of its own inherent system of meaning. One actual technique is known as 'bracketing'. This involves systematic steps to 'set aside' various assumptions and beliefs about a phenomenon in order to examine how the phenomenon presents itself in the world of the participant (Christiansen and Blumfield, 2010).

Using QSR NVivo 10 qualitative research software, thematic analysis was initially used to identify memorable life events and life changes. Analysis of experience drew on the phenomenological methods of analysis. Four steps were taken, borrowing from Giorgi's (2009) analytic procedures: (1) reading for a sense of the whole; (2) differentiating and clustering description into meaningful units; (3) psychological reflection; and (4) structural understanding and description.

LHCs were used individually and comparatively during the analysis. They provided grounding for individual analysis of events, used alongside development of and reflection on emerging units of meaning. They assisted in locating individual experiences in time and place by drawing attention to the changing social and political awareness of sexual abuse, and to potential differences in experience for participants 
whose abuse took place in other countries. Comparatively, they assisted in analysing differences and similarities of experience across all nine participants.

\section{Findings}

Seven women and five men took part in the full study. At the time of interview, the participants were aged between 30 and 59, with an average age of 39. One-quarter of the participants were born in and experienced abuse in the 1960s, one-quarter in the 1970s and one-quarter in the 1980s, which allowed for comparison of experiences over the course of significant social change and recognition of CSA.Three-quarters of the sample were White British, with the remaining quarter born in diverse parts of the world: two in two different North American countries, one in a Middle Eastern country and one in Southern Europe. Seven participants identified as heterosexual and three as gay or lesbian, one was uncertain about his sexuality and one described her sexuality as 'flexible'. Eight participants reported no disability. Eleven of the participants had some experience of higher education, and seven were working full-time. Four participants reported being in relatively stable marital or co-habiting relationships at the time of interview, with the remaining participants single, divorced or 'dating'.

The participants all reported having experienced CSA, but importantly, many of them also reported experiencing a range of other maltreatment experiences including witnessing domestic violence, physical abuse, emotional abuse and neglect. Nine of the 12 noted additional adversities in childhood such as parental relationship/marital breakdown, death of a sibling, parental mental health and/or substance abuse issues and frequent moves. Eight participants experienced penetrative contact sexual abuse for lengthy periods of time, all accompanied by physical or emotional coercion. The remaining four participants experienced non-penetrative contact sexual abuse.

Two participants were abused by multiple male perpetrators in relation to a single period of abuse. Five participants were abused by a single perpetrator for the duration of their experiences. These involved an uncle, grandfather, babysitter, family friend and teacher. The remaining five participants had multiple and separate periods of abuse carried out by different perpetrators, including uncles, a stepgrandfather, a father, a neighbour, family friends and a stepbrother.

Memorable life events (MLEs) reported by participants to have prompted disclosure in childhood were identified across six participant accounts. They were largely interpersonal and relational, although in a few cases the events reflected things that occurred to other family members or happened in the local community. Significant meanings were attached to all of the MLEs identified, and it was these meanings that fundamentally drove participants to enact their human agency by seeking help or protecting themselves. The remaining three participants did not identify MLEs in childhood that provided an impetus for disclosure; however, their circumstances appeared to prevent any potential influences that may have served to protect them at an earlier stage.

The relationship between MLEs and disclosure of abuse was not a straightforward one. Instead, contextual factors, relationships or events functioned to (a) moderate disclosure - or in other words, alter the strength or nature of the disclosure; (b) deteriorate disclosure - in other words, reverse any positive outcome that resulted from disclosure; or (c) mediate disclosure - in other words, inhibit disclosure. The influences in childhood that mediate, moderate or deteriorate disclosure are made 
up of similar risks and barriers. The difference between these three types of influence is that they had an impact on participants' disclosures differently. Thus, while they are distinct concepts in terms of the way they function to influence disclosure, the contexts that underpin these concepts derive from similar sources of risk. The remainder of the findings presented here describe these influences, with detailed examples provided to illustrate the complexity of the theme.

\section{Moderating influences}

Four participants across all of the age ranges recalled MLEs that they viewed as important motivators for disclosing their abuse, representing a self-identified shift from a previous position of inaction. However, their accounts revealed that they made decisions to adjust their actions in different ways in response to particular challenges they faced - in other words, their disclosures were moderated by a range of circumstances, contexts, relationships and other events. MLEs identified included: a coming of age-related event - no longer needing to go to the babysitter's house after school (Sid); two abuse-related events, both comprised of increasing violence and coercion (Jena and Aisha); and a peer-related event - a sleepover at a friend's house (Samantha). Moderated disclosures appeared in the form of the minimisation of abuse - withholding the full story - (Sid); and choosing self-reliance as a strategy - for example, avoidance of the perpetrator (Jena) and resistance of perpetrators (Aisha and Samantha).

Samantha was abused from infancy by her father and grandfather. Samantha's MLE was a peer-related event (a sleepover at a friend's house) at the age of eight. Her friend's father came into their room to say goodnight. Samantha recalled confusion about why he did not do 'special goodnights', like her father. This was a particularly vivid event and held important meaning for Samantha, who had previously not understood her experiences were abusive. Through comparison of her own experience with that of her friend's, she began to contextualise her experience differently - as one that did not happen to all children.
'At that age I thought it [sexual abuse] was, it was normal. I didn't like it, but I didn't know it wasn't what happened to, to everybody. I think I was about eight before I realised that it didn't happen to all little girls. I had a very sheltered life. I didn't have that much contact with other kids. But when I was eight, I had my first sleep over at someone else's house and I waited for her dad to come in and do special good nights. And it didn't happen.You know, he came in, he said goodnight, and he went.... I didn't say anything, but it set something off in me that made me think, "Your dad's weird!"... But it was about her dad being weird, not my dad ... yeah, but I really did think it was normal, and then that experience at my friend's got me thinking. I was still reluctant to broach the subject with my friend or anyone else though because of what happened earlier.'

This crucial event provided Samantha with a 'reference point' by which she could compare her father's actions with the actions of her friend's father. However, an early experience of attempted disclosure to a teacher - who accused her of lying - shaped her actions following her increasing recognition. Instead of choosing a strategy to 
stop the abuse that involved seeking help from adults, Samantha relied on her own resources for self-protection, which involved direct conflict with and resistance to the perpetrator(s):

\begin{abstract}
'Just, in the early few years, probably until I was about 12, I just wouldn't cooperate with them, um, I wouldn't get undressed, I wouldn't be where they wanted me to be, I wouldn't do what they wanted me to do. Um, and that's when they started making me do it, that's when it got a bit more aggressive I guess. From being about 13, I got a bit more subtle as well. Um, left tampons around the place, um, I hadn't actually started my period at that point, but um, it worked a little bit.'
\end{abstract}

This passage offers a fascinating insight into the creative and novel methods children may adopt to resist their abuse. Initially her strategy to directly resist the perpetrators was quite dangerous, and she experienced increased violence and aggression, although with time, she modified her approach to utilise more subtle strategies. Unfortunately for Samantha, her abuse did not diminish.

\title{
Deteriorating influences
}

Two participants clustered under this theme. They described MLEs that prompted them to seek help, although their familial contexts prevented positive resolution and worsened their circumstances well into adolescence and adulthood. MLEs identified included: a local child abuse case at a nursery (Shelly), and social work intervention in the family (Whitney). Although disclosures in both cases were heard, acted upon and progressed to the criminal justice system, their post-disclosure experiences were poor, lacking in practical and emotional support and trusted relationships. Moreover, their familial circumstances were chaotic and isolated, characterised by a range of other adversities such as parental substance misuse, marital breakdown and other victimisation and abuse.

By way of example, Whitney's MLE was a social care intervention in her family at the age of seven. She had been abused from infancy to age seven by a neighbour and her uncle, but had not told anyone about it. When social care professionals visited the home over concerns over her mother's mental health and subsequent neglect, her mother disclosed her own abuse over many years by her father and brothers. This was a significant event because in one moment, Whitney came to understand her mother's struggles, and this led to her own disclosure.

'When I was seven we had a social worker. Um, probably because, um my mum, my mum wasn't very well, aaaand, nobody knew why, aaand, when I was seven, we were called down, me and my sister.And, um, and uh, my mum and dad said, Tracey [name of sister changed], what did [social worker] say to you? And um, she said "Does Ralph [name of perpetrator changed] do you know, funny things with you?" Well of course I knew that he did, you know? Um, and, and, my mum said "And?” And [T] said "No." And, I said, "Well, he does [to] me." Right, and then it was like, um a blinding light, like a great big focus on me. And, then [T] had to admit, yes, the same. But she didn't 
react in the same way, she's not as strong as me, or certainly wasn't when I was a child. I was incredibly strong, because I had to go through so much.'

Despite her disclosure and the positive benefits she experienced as a result, things deteriorated because of her ongoing family circumstances and relationships that resulted in Whitney taking on primary responsibility around the household for her whole family. Whitney particularly cited her 'loss of childhood' as the start of her lifelong mental health problems that have meant that she has never been able to work or have a family of her own.

Shelly was abused by a family friend when she was six and then again by her grandfather at the age of seven until she disclosed the abuse at the age of 11 . She remained silent about her abuse until that point, not recognising the abuse as wrong. She became aware of a child sexual abuse case at a local nursery school in the mid1980s, where it emerged that a nursery worker had abused a considerable number of children:

\begin{abstract}
'This place over in $[\mathrm{M}]$ called [N-House], and it was a play school, lots of children were being abused by the/by the owner, and the/don't know what you call them, not teachers as such but nursery worker! They were being abused, and it all come to light, there was 26 children involved, and me being the age, I was listening and thinking, that's when I'd worked out that everything that was happening was wrong. My mum going through this with [C, her sister] which is why we then came forward to say what happened. But I think if that hadn't happened with [C], maybe I would have carried it to my grave.' [[why is some text underlined?]]
\end{abstract}

Shelly's narrative also highlighted a further memorable event that reinforced her newly formed cognitions of abuse. It was in the same period that the local abuse case emerged that her abuser was making plans to take Shelly, alone, on a world cruise. The abuse was further escalating, becoming more aggressive and violent:
'Yeah.With my grandfather, he booked for me to go on a cruise, on a world cruise to the Amazon, just trying to remember '87 I was due to go. Um, he was the one who was abusing me for years, and he lived in [B] and took me down to my auntie's and took me to his flat first. And some really really awful things happened there. It was then that I knew, I really knew what was, I'd worked it out by then that it was really really wrong.... I went to my teachers in school, my mum, everybody was called in. Um, and I got taken to a police safe house, been examined, been questioned, all because I was scared of what was gonna happen to me on this cruise ship in a room with him on my own for two months. I was absolutely petrified. And I didn't quite realise the implications, what he'd done. But I knew I wasn't the only one, and that something was wrong, and I feared for myself if I had gone there.' [[why is some text underlined?]]

Shelly's memorable event - her grandfather's escalating behaviours - as distressing as they were, acted as positive reinforcement in this case to her already growing awareness that her experiences were not normal. Shelly disclosed, but had a mixed 
experience. Her teachers and her mother believed her disclosure, her grandfather was arrested, the abuse stopped and an investigation ensued. She felt positive that the outcome would be good, because of what she had observed at the local nursery school (for example, police involvement, arrests). However, the result of this chain of events mitigated her emerging life change (seeking help from adults; disclosure) and, in fact, reversed it for a very long time. This passage articulates the disappointment at Shelly's lack of justice:

\begin{abstract}
'He/he was arrested, he was questioned, but because he was old and he was frail, they weren't going to proceed it any further because they said he would be dead soon. And he did actually die within a year or two. But that was just devastating, because I wanted my justice, not justice for HIM. I wondered why I had even told anyone! The hardest thing of my life to do, and nothing came of it. Not even a counsellor. Where was the counselling, where was anything. Where were they? It was/with my mum it's always, "keep quiet, don't tell people", don't bring shame, you know, and then all our family were, 'coz I've got big life story where I used to do drugs, my life went bad. And you sort of get, "help me", just help. Listen to me and help me.' [[why is some text underlined?]]
\end{abstract}

The only person in her life whom she trusted was her stepfather:

'Then coming back to my mum and who I now call my dad - he's actually my stepdad but he took us on from a very young age and he's been great to me all my life, even now that they're divorced. He's the only one I trusted at all during that horrible time, because my mum tried to forget I was abused.'

Mitigating her emergent change even further, then, was the breakdown of her parents' marriage that occurred around the same period, just around the time she was 12.This key life event was experienced as a loss of a trusted adult and ultimately catalysed what Shelly called as the point when her life 'went bad':

\begin{abstract}
'Um, the day my dad left really, is - I turned to, started smoking weed/well cannabis at the time, started smoking that. Acid was very big in/in my era. Just didn't care, just wanted to blot out everything um. Very promiscuous from a young age, I'd say roughly about 13, coming on to 14 when I become sexually active, um.' [[why is some text underlined?]]
\end{abstract}

\title{
Mediating influences
}

Three participants clustered under this final relationship between MLEs and disclosure. These participants made no reference to MLEs in their childhood that were associated with decisions to tell someone about their abuse. None, in fact, identified what they considered to be any sort of life change associated with their CSA experiences in their childhood period. The contextual circumstances of their lives, however, provide a possible explanation for the absence of self-identified MLEs. All three of these participants were living in family circumstances that were isolating, closed, chaotic or where other adversities and abuse were taking place. 
Paula's circumstances provide a good example of the way in which shame can overshadow the potential for help-seeking following CSA. Paula, born in a Southern European nation that is also where her abuse took place, was abused by her uncle. Paula's narrative of childhood is heavy with reference to shame (a text search in NVivo identified over 11 references to shame in Paula's account in comparison to five in another, and three or fewer in the remainder of the interviews). Her narrative stood out among all the others in this respect. When asked how she made sense of her abuse experiences, she said: "I don't know, but I know there was a lot of shame around sexual and sexual feelings."

Later in the interview, Paula described the way in which her shame prevented her from talking to her mother. She attributed her shame to her physical reaction to the abuse, in spite of knowing that her uncle's actions did not feel right:

'I think it's because my body reacted to the um whatever my uncle was doing to me, that I felt shame around that and hence, couldn't tell my mother. It wasn't like we lived in a family where we could talk about sexuality. I mean, my mother said, "I thought they taught that stuff in school.",

Sexuality, then, was a closed issue in her household as it was assumed that responsibility for addressing and teaching sexuality lay elsewhere. The shame Paula felt following the abuse was a powerful barrier to her agency during childhood, and is, in fact, something that has lasted well into her adulthood.

\section{Discussion}

A key concept to emerge from the study is 'emergent change'- and for the purposes of this article, the emergent change of interest is disclosure of sexual abuse. This is central to the study, as the analysis hinged on the success or otherwise of life change (disclosure) to emerge following an important life event. 'Emergent change', then, can be defined as self-identified aspirational change (for example, the desire to tell someone about the abuse from a previous position of silence about the abuse). 'Emergent change' might be better understood as positive change in its infancy, but which is very fragile because of its tentative nature. It is also fragile because of the complex, difficult and challenging circumstances surrounding it. Considering this concept within the broader life course literature, this concept differs from turning points that require, according to Sampson and Laub (2005), change following the passage of some time. For the participants in this study, negative and unexpected change occurred almost immediately in reaction to a memorable life event or convergence of several life events. Emergent change in the form of disclosure is most similarly aligned with concepts such as incremental nudges (in Samantha's case, where, over time she began to contextualise her experiences in response to external precipitants) or eddies/drifts (in Whitney or Shelly's cases, where their disclosures - which they had anticipated would have a positive impact on their lives - went in unexpected, and unpleasant, directions).

Although unique in type and content, the MLEs identified all shared characteristics that meet the definition of Pillemer's $(1998,2001)$ concept of 'momentous' life events. These characteristics were obvious in the participants' telling of the event. For example, the events identified mostly represented a single event that occurred at a specific time 
and place, and the descriptions often contained contextual details of the participants' circumstances at the time. Descriptions often included details about the timeframe of the event, the surroundings and who was present. Sometimes the accounts included sensory imagery, such as sights and smells. In some cases, the participants used gestures that helped me to visualise the scenarios (for example, one participant said "I was sat here, he was sat there", pointing opposite to where I sat) and sometimes the participants used the present tense as if the events were happening right then and there (for example, a participant said "he has big fat fingers that he tickles and touches me with"). In addition, participants' actual experience of remembering the events evoked strong feelings such as anger, sadness and disappointment, but in some cases, positive emotions such as pride in resisting the perpetrator were articulated.

Pillemer postulated that important meanings attached to these events could have important impacts, guiding and directing action after the event. The particular MLEs identified by participants reflected this process, resulting in aspirational decisions to seek help and stop the abuse. The MLEs identified reflect a range of unique events including abuse-related events (escalating abuse); a peer-related event (spending time with a friend); a community-related event (a local child abuse case); a family-related event (social care intervention); and a transitional event (entering adolescence). Some of these have been captured in the findings of other research, despite not having been conceptualised as such (Jensen et al, 2005; Author's own, 2013 [[reference?]]; Cossar et al, 2013; Malloy et al, 2013).

MLEs are impossible to predict because they are unique and personal and will vary considerably from one individual to the next. The importance of them, however, lies in the meaning that individuals attach to them. This is responsible for driving human agency in the form of disclosure. Park and Folkman's (1997) meaning making model helps in making sense of how meaning operates. They propose that an individual's perception of discrepancies between their appraised meaning of a particular event (the situational meaning of the event) and their global meaning (their world view) creates distress, which gives rise to efforts (coping strategies) to reduce the discrepancy and resultant distress. In the case of Samantha, her global world view at age eight was that all fathers act in sexual ways towards their daughters. This was at odds with her experience during the sleepover at her friend's house, resulting in confusion about her world view. Ultimately, this led to a cognitive shift in her world view, resulting in her attempts to try and stop her abuse.

The findings, however, also show that the relationship between MLEs and disclosure is not a direct one. Participants recalled that a range of circumstances conspired against them, moderating or deteriorating their disclosures. Poor parental responses to disclosures, for example, encouraged one participant to withhold the full extent of his abuse, reflecting findings in Ullman and Filipas' (2005) research. Poor, or nonexistent, reactions also forced three participants to self-protect through avoidance of the perpetrator or resistance, actions that have been documented in a range of studies on disclosure and coping with abuse (Oaksford and Frude, 2004; LeClerc et al, 2010 [[not in the References?]]).

Circumstances can also conspire to moderate and deteriorate disclosures, but also to prevent - or mediate - them entirely. The wider research on risk and adversity is relevant here, with the experiences and circumstances of participants reflecting a diversity of issues that can be understood within an ecological framework. Childlevel factors, such as an inability to recognise abuse and understand it as 'acceptable' 
(Cossar et al, 2013), and emotional barriers such as shame that prevented help-seeking (Browne and Finkelhor, 1986), were evident in some accounts. Familial-level contexts including closed, uncommunicative and unemotional relationships, social isolation and wider family violence and adversity have been associated with non-disclosure (Alaggia, 2010), and were circumstances observed in the current study.

There are, inevitably, some limitations to this study. The sample is small, and therefore generalisations to a wider population are not possible, but neither are generalisations desirable in a qualitative study. The sample is, however, biased in a number of ways. The majority of the sample are White British and, although there was some diversity among the sample in terms of their country of origin, the small number of these participants (and the variability between their countries of origin) mean that specific patterns were not readily identifiable. This was a self-selected sample, which means that those who chose to take part may be different in some way than those who did not.

The interpretation of participants' life course narratives in a cross-sectional, retrospective study represents a further limitation - and an important message for future research - to research undertaken within a constructivist ontological framework. As Holland and Thomson (2009) found in their re-visitation and re-interpretation of longitudinal qualitative data on turning points in youth studies, important changes in interpretation were brought about by the accumulation of biographical data. Simply put, participants in the longitudinal study identified important turning points at one point in time, but at later data collection points, recollected different turning points, failing to mention the ones that they deemed crucial in earlier interviews. It is possible, therefore, that had this been carried out longitudinally and prospectively, future interviews with the participants in this study might uncover different or new information. The constructed nature of individual biography is ongoing throughout the life course, as individuals change and re-shape their life histories.

\section{Conclusions and recommendations}

The research has illustrated that some events at the family and societal level have the potential to inform and empower children and young people with the knowledge that abuse is wrong. Policy implications include the possibility that media coverage of sexual abuse may encourage contextualisation of experiences among some children. It may have a positive impact on some children who are beginning to contextualise their experiences within their peer or familial environments and, given the right conditions, empower them to seek help.

With respect to professionals working with children and adults around the children, the research has highlighted the importance of recognising signs and symptoms of abuse, and ensuring a sensitive response to children and young people who may be trying to disclose their experiences. While these are not new findings or recommendations, they require continual reinforcement given the very recent cases that have emerged that show how children's disclosures continue to go unnoticed or ignored. Professionals working with children, young people and adult survivors may find these findings on memorable events useful in therapeutic contexts, enabling practitioners to understand, recognise and engage with situational meanings and their relationship to change with a view to supporting and strengthening emergent change.

It is not possible to predict or control potentially influential memorable events because of their uniqueness and variability. However, memorable events provide one 
further avenue through which children, young people and adults may be empowered, encouraging them to seek help where and when they need to. Messages from the literature on disclosure are relevant here. Children and young people need to be noticed, heard and believed following any disclosures. Disclosure does not mean that problems end for children, and therefore ongoing emotional and practical support is required to ensure children have the best chances of moving on from CSA. The research findings, in context with the broader literature, seem to suggest that a debate is required about the ways in which professionals or other supportive adults can question children directly about abuse if it is suspected.

Future research should investigate the ways in which people alter their actions in response to the resources available to them, as this is currently neglected in the literature. More specifically, while the literature identifies the barriers children face to disclosure that shut down their opportunities to seek help and literature on resistance provides knowledge about the ways children fight back against their abusers, there is no research that bridges these two areas to understand the choices children and young people make to keep themselves safe when faced with limited or poor options. Greater consideration should be given to the process by which children come to contextualise their experiences as abusive or as wrong, and in particular, the role that friendships and wider social networks play in this. Further qualitative research would benefit from incorporating a more diverse sample to understand whether memorable events or emergent changes are different within the lives of people in a variety of cultural and ethnic backgrounds.

\section{Acknowledgements}

The findings presented in this article are based on the author's $\mathrm{PhD}$ research that was funded and supported by the National Society for the Prevention of Cruelty to Children (NSPCC), where the author was employed during the period of study. The author also acknowledges and is grateful for the contributions of the participants without which this work would not have been possible.

\section{References}

Alaggia, R, 2010,An ecological analysis of child sexual abuse disclosure: Considerations for child and adolescent mental health, Journal of the Canadian Academy of Child and Adolescent Psychiatry 19, 1, 32-9

Allnock, D, Miller, P, 2013, No one noticed, no one heard: A study of childhood disclosures of abuse, London: NSPCC

Arias, B, Johnson, C, 2013, Voices of healing and recovery from childhood sexual abuse, Journal of Child Sexual Abuse 22, 7, 822-41

Axinn, W, Pearce, L, Ghimire, D, 1999, Innovations in life history calendar applications, Social Science Research 28, 3, 243-64

Banyard,V,Williams, L, 2007, Women's voices on recovery:A multi-method study of the complexity of recovery from child sexual abuse, Child Abuse \& Neglect 31,3, 275-90

Belli, RF, 1998, The structure of autobiographical memory and the event history calendar: Potential improvements in the quality of retrospective reports in surveys, Memory 6, 4, 383-406

Berney, LR, Blane, DB, 1997, Collecting retrospective data: Accuracy of recall after 50 years judged against historical records, Social Science \& Medicine 45, 10, 1519-25 
Bogar, C, Hulse-Killacky, D, 2006, Resiliency determinants and resiliency processes among female adult survivors of childhood sexual abuse, Journal of Counselling $\mathcal{E}$ Development 84, 3, 318-27

Browne, A, Finkelhor, D, 1986, Impact of child sexual abuse:A review of the research, Psychological Bulletin 99, 1, 66-77

Campis, L, Hebden-Curtis, J, Demaso, D, 1993, Developmental differences in detection and disclosure of sexual abuse, Journal of the American Academy of Child and Adolescent Psychiatry 32, 5, 920-24

Carlsson, C, 2012, Using 'turning points' to understand processes of change in offending, British Journal of Criminology 52, 1-16

Christiansen, T, Brumfield, K, 2010, Phenomenological designs: The philosophy of phenomenological research, in CJ Sheperis, JS Young and MH Daniels, eds, Counseling research: Quantitative, qualitative, and mixed methods, Upper Saddle River, NJ: Pearson Education, Inc

Conway, M, Justice, L, Morrison, C, 2014, Beliefs about autobiographical memory, The Psychologist 27, 7 (https://thepsychologist.bps.org.uk/volume-27/edition-7/ beliefs-about-autobiographical-memory)

Cossar,J, Brandon, M, Bailey, S, Belderson, P, Biggart, L, 2013, 'It takes a lot to build trust.' Recognition and telling: Developing earlier routes to help for children and young people, A report for the Office of the Children's Commissioner for England (www.uea.ac.uk/ documents/3437903/0/OCC+Recognition+and+Telling+report.pdf/923aec110221-4d54-8c77-f83189e9e02d) [[I changed the url, okay?]]

Del Bianco, A, 2015, A method for collecting life course data:Assessing the utility of the life grid, in NWorth and I Hardill, eds, Researching the life course: Critical reflections from the social sciences, Bristol: Policy Press [[pages?]]

Denzin, N, Lincoln, Y, 2005, Introduction: The discipline and practice of qualitative research, in NK Denzin andYS Lincoln, eds, The Sage handbook of qualitative research, 4th edn, Thousand Oaks, CA: Sage Publications

Freedman, D, Thornton, A, Camburn, D, Alwin, D, Young-Demarco, L, 1988, The life history calendar: A technique for collecting retrospective data, Sociological Methodology 18, 37-68

Giddens, A, 1991, Modernity and self identity: Self and society in the late modern age, Cambridge: Polity Press

Giele, J, Elder, G, eds, 1998, Methods of life course research: Qualitative and quantitative approaches, Newbury Park, CA: Sage Publications

Giorgi, A, 2009, The descriptive phenomenological method in psychology, Pittsburgh, PA: Duquesne University Press[[cited?]]

Goodman, L, Corcoran, C, Turner, K, Yuan, N, Green, B, 1998, Assessing traumatic event exposure: General issues and preliminary findings for the Stressful Life Events Screening Questionnaire, Journal of Traumatic Stress 11, 3, 521-42

Hershkowitz, I, Lanes, O, Lamb, M, 2007, Exploring the disclosure of child sexual abuse with alleged victims and their parents, Child Abuse \& Neglect 31, 2, 111-23

Holland, J, Thomson, R, 2009, Gaining a perspective on choice and fate: Revisiting critical moments, European Societies 11, 3, 451-69

Holstein, J, Gubrium, J, 2000, Constructing the life course, New York: General Hall, Inc Howe, M, 2013, Memory development: Implications for adults recalling childhood experiences in the courtroom, Nature Reviews: Neuroscience 14, 869-76 
Hutchinson, E, 2010, A life course perspective, in E Hutchinson, ed, Dimensions of Human Behaviour, 4th edn, Thousand Oaks, CA: Sage Publications, 1-38

Jensen, T, Gulbrandsen, W, Mossige, S, Reichelt, S, Tjersland, O, 2005, Reporting possible sexual abuse:A qualitative study on children's perspectives and the context for disclosure, Child Abuse \& Neglect 29, 12, 1395-413

Ladlow, L, Neale, B, 2016, Risk, resource, redemption? The parenting and custodial experiences of young offender fathers, Social Policy \& Society 15, 1, 113-27

Loftus, E, Marburger,W,1983, Since the eruption of Mt St Helens, has anyone beaten you up? Improving the accuracy of retrospective reports with landmark events, Memory \& Cognition 11, 2, 114-20

London, K, Bruck, M, Ceci, S, Shuman, D, 2005, Disclosure of child sexual abuse: What does the research tell us about the ways that children tell?, Psychology, Public Policy, and Law 11, 1, 194-226

Malloy, L, Brubacher, S, Lamb, M, 2013, 'Because she's one who listens': Children discuss disclosure recipients in forensic interviews, Child Maltreatment 18, 4, 245-51

Morselli, D, Dasoki, N, Gabriel, R, Gauthier, J-A, Henke, J, Le Goff, JM, 2016, Using life history calendars to survey vulnerability, in M Oris, C Roberts, D Joye and M Ernst Stähli, eds, Surveying human vulnerabilities across the life course, vol 3, New York: Springer International Publishing

Oaksford, K, Frude, N, 2004, The process of coping following child sexual abuse: A qualitative study, Journal of Child Sexual Abuse 12, 2, 41-72

Park, C, Folkman, S, 1997, Meaning in the context of stress and coping, Review of General Psychology 1, 2, 115-44

Pillemer, D, 1998, Momentous events: Vivid memories, Cambridge, MA: Harvard University PressPillemer, D, 2001, Momentous events and the life story, Review of General Psychology 5, 2, 123-34

Roberts, K, Powell, M, 2001, Describing individual incidents of sexual abuse:A review of research on the effects of multiple sources of information on children's reports, Child Abuse \& Neglect 25, 1643-59

Roller, C, Martsolf, D, Draucker, C, Ratchneewan, R, 2009, The sexuality of childhood sexual abuse survivors, International Journal of Sexual Health 21, 1, 46-60

Sampson, R, Laub, J, 2005, A life course view of the development of crime, The ANNALS of the American Academy of Political and Social Science 602, 12-45

Thomson, R, Bell, R, Holland, J, Henderson, S, McGrellis, S, Sharpe, S, 2002, Critical moments: Choice, chance and opportunity in young people's narratives of transition, Sociology 36, 2, 335-54

Ullman, S, Filipas, H, 2005, Gender differences in social reactions to abuse disclosures, post-abuse coping, and PTSD of child sexual abuse survivors, Child Abuse \& Neglect $29,7,767-82$ 